COMMENT. Relapses in patients initially diagnosed with ADEM are reported in $10 \%$ of cases (Tenembaum et al, 2002; see Ped Neur Briefs Nov 2002;16:81). Residual disability was not related to MRI findings at onset in this series, but it was correlated with the occurrence of optic neuritis. Absence of oligoclonal bands in the CSF and long-term MRI findings will distinguish ADEM from MS in the $10 \%$ of patients showing a biphasic course with single relapse. In the present report, corpus callosum (CC) and single well-defined lesions in the MRI occurred more frequently in patients with relapse than those with a monophasic course. Corpus callosum long axis perpendicular lesions are defined as welldefined ovoid lesions perpendicular to the CC long axis. They are sometimes known as 'Dawson's fingers' and are considered a relatively specific indicator of MS. However, even using initial MRI lesions, survival analysis methods and a 5-year mean follow-up, the authors found it difficult to predict conversion to MS after a first episode of acute CNS inflammatory demyelination. Corpus callosum and periventricular demyelination characteristic of MS was present in $29 \%$ of 31 childhood cases of ADEM reported from Australia (Hynson et al, 2001; see Ped Neur Briefs June 2001;15:46).

\title{
ADEM: AGE AT ONSET AND NEUROPSYCHOLOGICAL OUTCOME
}

The influence of age at onset of acute disseminated encephalomyelitis (ADEM) on cognitive, educational, and social functioning was evaluated in 19 children $(10<5$ years of age) admitted to the Royal Children's Hospital, Melbourne, Australia. Compared to controls, stratified for age and socioeconomic status, patients who developed ADEM before 5 years of age had a lower mean intelligence quotient $(\mathrm{p}<0.01)$, significantly lower scores on reading and spelling $(\mathrm{p}<0.001)$, and a higher incidence of severe behavioral and emotional problems. The young onset group also obtained a significantly lower standard score on spelling in comparison with the old onset group $(\mathrm{p}<0.05)$. No significant differences were found on cognitive measures in children treated or not treated with steroids; the number not treated was too small for a meaningful conclusion. The frequency of MRI abnormalities was similar in the young and old onset groups, and the proportion of children experiencing one or more relapses was also similar. (Jacobs RK, Anderson, VA, Neale JL, et al. Neuropsychological outcome after acute disseminated encephalomyelitis: Impact of age at illness. Pediatr Neurol September 2004;31:191-197). (Respond: Dr Jacobs, Department of Psychology, Royal Children's Hospital, Flemington Road, Parkville, Melbourne, Victoria, 3054, Australia).

COMMENT. Long-term neuropsychological dysfunction may occur in children who develop ADEM in early childhood, despite the absence of persisting neurologic deficits. Children under 5 years of age recovering from ADEM should be tested for possible cognitive, behavioral, and emotional problems that require educational and psychological intervention. 